\title{
Spironolactone-induced bilateral gynecomastia in a man detected by SPECT myocardial perfusion imaging
}

\author{
Ayman A. Farag, MD, ${ }^{\mathrm{a}}$ Efstathia Andrikopoulou, MD, ${ }^{\mathrm{a}}$ and Fadi G. Hage, $M D^{\mathrm{a}, \mathrm{b}}$ \\ a Division of Cardiovascular Disease, Department of Medicine, University of Alabama at \\ Birmingham, Birmingham, AL \\ ${ }^{\mathrm{b}}$ Section of Cardiology, Birmingham Veterans Affairs Medical Center, Birmingham, AL
}

Received Apr 15, 2016; accepted Apr 18, 2016

doi:10.1007/s12350-016-0523-2

\section{CASE PRESENTATION}

A 60-year-old man with alcoholic cirrhosis underwent regadenoson SPECT myocardial perfusion imaging as a part of liver transplant evaluation. His current medications included spironolactone $50 \mathrm{mg}$ daily, furosemide, and nadolol. The rest and stress ECGs and the perfusion images were normal (Figure $1 \mathrm{~A}$ ). The left ventricular ejection fraction was $70 \%$. The raw images showed tracer uptake in both breasts and both breasts appeared large (Figure 1B).

\section{Comments}

We attribute the gynecomastia in this man to spironolactone. Although liver cirrhosis can cause gynecomastia, it usually does not result in increased tracer uptake in the breast tissue. This is the first such case in our experience in hundreds of patients studied before liver transplantation. ${ }^{1}$ The gynecomastia can be painful and may be reversible once spironolactone is discontinued. A medication history may prevent unnecessary testing to elucidate the etiology. Discontinuation of spironolactone, and substitution with eplerenone if indicated, is recommended.

Electronic supplementary material The online version of this article (doi:10.1007/s12350-016-0523-2) contains supplementary material, which is available to authorized users.

Reprint requests: Fadi G. Hage, MD, Division of Cardiovascular Disease, Department of Medicine, University of Alabama at Birmingham, Lyons Harrison Research Building 306, 1720 2nd AVE S, Birmingham, AL 35294; fadihage@uab.edu

J Nucl Cardiol 2017;24:742.

$1071-3581 / \$ 34.00$

Copyright (c) 2016 American Society of Nuclear Cardiology.

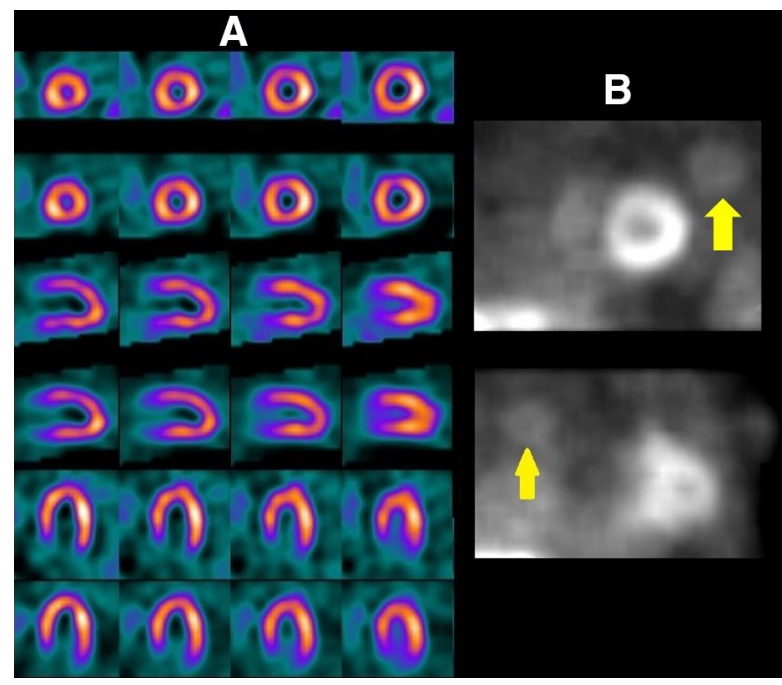

Figure 1. (A) Stress and rest Tc-99m SPECT MPI showing normal perfusion. (B) Raw image showing tracer uptake in both breasts (yellow arrows); the video of the rotating image is available online in the data supplement.

\section{References}

1. Iskandrian AE, Garcia EV. Nuclear cardiac imaging: principles and applications, vol. 5. Oxford: Oxford University Press; 2015. 